\title{
Paternal transmission of congenital myotonic dystrophy
}

\author{
Christine E M de Die-Smulders, H J M Smeets, W Loots, H B M Anten, J F Mirandolle, \\ J P M Geraedts, C J Höweler
}

Department of Clinical Genetics, Maastricht University, PO Box $1475,6201 \mathrm{BL}$

Maastricht, The

Netherlands

C E M de Die-Smulders

Department of Molecular Genetics, Maastricht University, The Netherlands

H J M Smeets

W Loots

J P M Geraedts

\section{Department of}

Neurology, Maasland

Hospital, Sittard, The

Netherlands

H B M Anten

\section{Department of}

Neurology, de Wever

Hospital, Heerlen, The

Netherlands

J F Mirandolle

Department of

Neurology, University

Hospital Maastricht,

The Netherlands

C J Höweler

Correspondence to: Dr de Die-Smulders.

Received 9 December 1997 Revised version accepted for publication 22 April 1997

\begin{abstract}
We report a rare case of paternally transmitted congenital myotonic dystrophy (DM). The proband is a 23 year old, mentally retarded male who suffers severe muscular weakness. He presented with respiratory and feeding difficulties at birth. His two sibs suffer from childhood onset DM. Their late father had the adult type of DM, with onset around 30 years. Only six other cases of paternal transmission of congenital DM have been reported recently. We review the sex related effects on transmission of congenital DM. Decreased fertility of males with adult onset $D M$ and contraction of the repeat upon male transmission contribute to the almost absent occurrence of paternal transmission of congenital DM. Also the fathers of the reported congenitally affected children showed, on average; shorter CTG repeat lengths and hence less severe clinical symptoms than the mothers of children with congenital DM.

We conclude that paternal transmission of congenital DM is rare and preferentially occurs with onset of $D M$ past 30 years in the father.

(F Med Genet 1997;34:930-933)
\end{abstract}

Keywords: myotonic dystrophy; congenital; paternal transmission

Myotonic dystrophy (DM) is an autosomal dominant disorder characterised by myotonia and muscle weakness and complicated by multisystem manifestations. Four separate disease types are recognised based on age at onset and predominant symptoms: mild, adult, childhood, and congenital DM. ${ }^{1-3}$ The clinical picture of congenital DM is characterised by neonatal hypotonia and generalised muscle atrophy with potentially life threatening respiratory and feeding difficulties. Typically, the baby has bilateral facial weakness with a tent shaped mouth. Congenital talipes or other joint contractures are other commonly associated findings. Polyhydramnios and reduced fetal movements are often noted in the preceding pregnancy. ${ }^{4}$ If the congenitally affected baby survives beyond the first weeks, the muscle weakness improves, but mental retardation is very common. The childhood type of DM is less well defined. The age at onset is usually between 1 and 10 years. Speech and learning difficulties are the only early signs in most cases. Some children present with myotonia and muscle weakness, but usually not before school age. ${ }^{15}$

DM occurs as a result of expansion of the number of CTG trinucleotides in the $3^{\prime}$ untranslated region of the DMPK gene. ${ }^{6}$ CTG repeat length usually increases with transmission to subsequent generations, explaining the phenomenon of anticipation at the clinical level. ${ }^{37} \mathrm{~A}$ general, but not absolute correlation is seen between CTG repeat length and age of onset and severity of clinical symptoms. ${ }^{2}$ Sex differences in transmission are well recognised. Most notably, congenital DM almost exclusively originates from the mother. ${ }^{4}$ Childhood and adult onset DM, on the other hand, may be transmitted by an affected parent of either sex. Paternally transmitted congenital DM is a rare event. Its infrequent occurrence, therefore, is of interest and suggests some significant difference in the mechanism of paternal as opposed to maternal transmission. Six cases have been published recently. ${ }^{8-11}$ In this paper, we report on a seventh case of paternal transmission of congenital DM.

\section{Case reports}

Patient 1 was born at term by spontaneous vaginal delivery. He was hypotonic at birth and received supplemental oxygen because of respiratory difficulties. Artificial ventilation, however, was not required. Nasogastric feeding was necessary owing to his poor sucking and swallowing problems. He had a talipes deformity of his left foot. His hypotonia and feeding problems gradually improved over the first few months of life but developmental delay was noted in later years. He sat unsupported at 10 months and walked at 18 months of age. At the age of 13 he was found to have a tented mouth, dysarthria, a nasal voice, a high arched palate, and myotonia of his hands (fig 1). His mental development was borderline (IQ 75, WISC) and he needed special education from the age of 7 . On recent review at the age of 23 , he was severely dysarthric. He complained of swallowing difficulties, recurrent abdominal pains, and diarrhoea. He had a myopathic face with severe weakness and atrophy of his facial and neck muscles (fig 1). In addition, his distal and proximal arm muscles and lower leg muscles were similarly affected giving bilateral foot drop. Testicular atrophy was also evident. $\mathrm{He}$ works in sheltered employment.

Patient 2 is the older brother of patient $1 . \mathrm{He}$ was born at term with no neonatal hypotonia or respiratory or feeding difficulties reported. His developmental milestones were within the normal range. At the age of 8 years he presented 

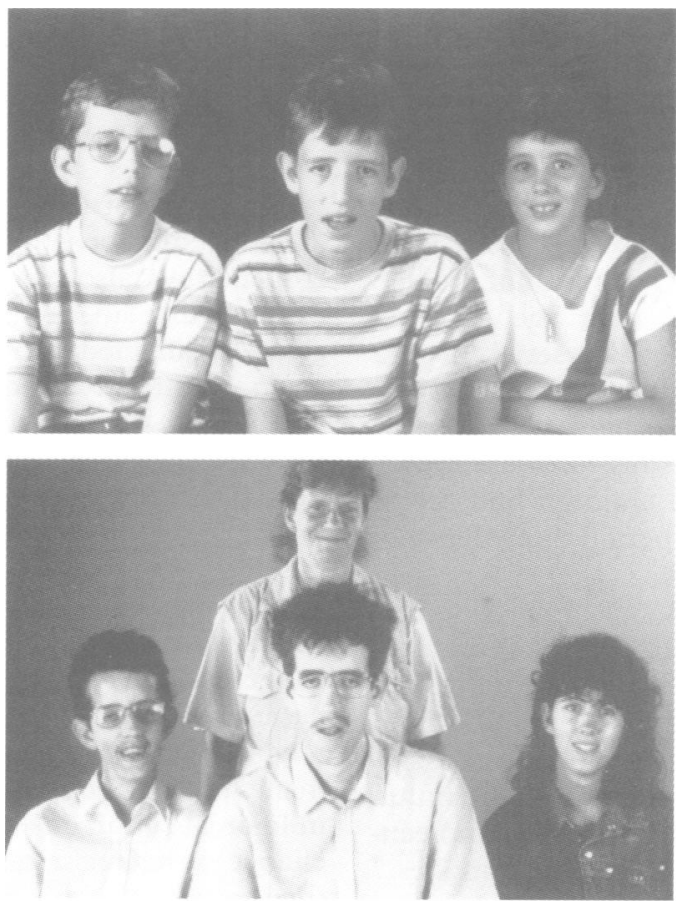

Figure 1 Upper row, from left to right: patients 2, 1, and 3 at the ages of 14,13, and 10 years, respectively. Lower row, from left to right: patients 2,1 , and 3 photographed 10 years later, with their normal mother. Note progression of facial weakness, especially in patients 1 and 2 . (All photographs reproduced with permission.)
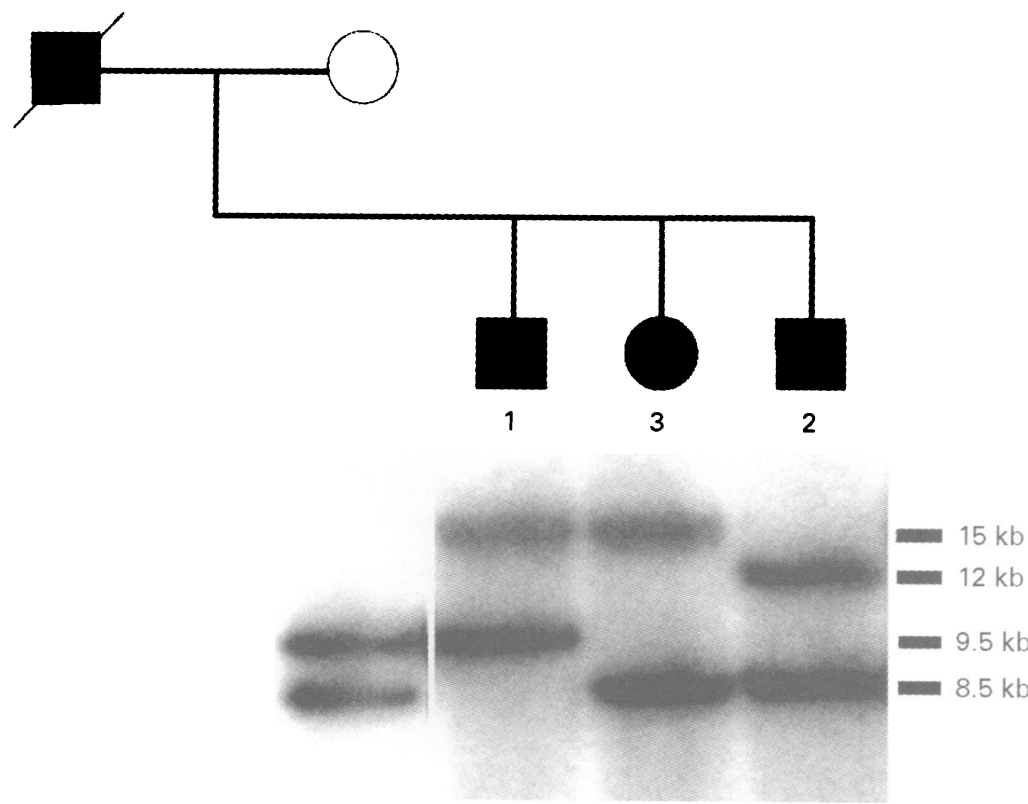

Figure 2 Southern blot analysis of patients 1, 3, and 2 and their mother. The Southern blot analysis with probe pGP1.5 was performed on HindIII digested DNA from peripheral blood leucocytes. Normal fragments are 8.5 and $9.5 \mathrm{~kb}$. Expansions are calculated respective to the larger normal fragment, 5-6 kb for patients 1 and 3 and 2-3 kb for patient
2espectively.

with a shuffling gait. Over the next few years his muscular symptoms worsened. By the age of 14 he had severe dysarthria, facial weakness, and mild atrophy of the calf and anterior tibial muscles. He was found to be of low/normal intelligence (IQ 90, WISC). In addition he had stigmata of neurofibromatosis type 1 , from which his mother also suffered. On recent review, aged 24 years, he showed facial weakness, atrophy of the facial and neck muscles, and grip myotonia (fig 1). Distal limb weakness was relatively mild.
Patient 3 is the younger sister of cases 1 and 2 . She first presented at the age of 7 years with learning difficulties and needed special education. By 9 years of age she was clumsy and slow and was found to have myotonia. Evaluation at the age of 20 showed a mildly retarded girl with normal speech. Neurological examination showed only mild facial and neck muscle weakness and a high arched palate (fig 1). Severe myotonia was evident in her hands. Walking on her heels was difficult, but otherwise her extremities were not affected.

The father of the three affected children was of normal intelligence. He presented at the age of 30 when he noticed weakness of the hands because he could not hold his newborn daughter for long without tiring. In addition his voice had altered, becoming more nasal and, when asleep, he had a lid lag. Neurological examination at that time showed mild weakness of his facial muscles and hands and myotonia was confirmed by electromyogram. At the age of 31 he died from a malignant brain tumour. Six of his 13 sibs showed definitive symptoms of adult onset DM.

The mother was examined at the age of 45 and was found to have no signs or symptoms of DM. She was known to suffer from neurofibromatosis type 1 .

\section{DNA analysis}

Chromosomal DNA was isolated from peripheral blood cells and analysed for expansion of the CTG repeat, according to methods previously described. ${ }^{3}{ }^{12} 13$ The polymorphic markers used were the extragenic CA repeat D19S112 and the intragenic RFLPs $H h a I$ and HinfI. ${ }^{14}$ Patients 1, 2, and 3 showed an expansion of the CTG repeat, varying from 5-6 $\mathrm{kb}(\mathrm{n}=1700-2000 \mathrm{CTG}$ repeats) for cases 1 and 3 to $2-3 \mathrm{~kb}(\mathrm{n}=700-1000)$ for case 2 (fig 2 ). The repeat sizes fall within the overlap region of adult onset and congenital myotonic dystrophy. Their mother was unaffected and had two normal CTG alleles $(n=5$ and $n=14)$. Their affected father had died and could not be tested. Therefore we tested the family with intragenic RFLPs and the CA repeat D19S112 to determine the risk haplotype. ${ }^{15}{ }^{16}$ All affected paternal family members, including patients 1 , 2 , and 3, carried the same haplotype (data not shown). We concluded that all three had inherited the expanded CTG repeat from their affected father.

\section{Discussion}

In this paper we report on a patient with paternally inherited congenital DM. His two sibs had the childhood type of DM and their father suffered from the adult type of DM, with age at onset around 30 years. Congenital DM is almost exclusively maternally transmitted. ${ }^{4} \mathrm{Six}$ cases of paternally transmitted congenital DM have recently been reported. ${ }^{811}$ Ohya et al ${ }^{10}$ described a father of two congenitally affected children who was still asymptomatic at the age of 42 and showed minimal expansion of the CTG trinucleotide. Nakagawa et al reported two sibs with congenital DM whose father first developed symptoms of DM at 39 years. The 
father of the patient described by Bergoffen $e t$ $a t^{8}$ showed mild symptoms at the age of 53 . The father of the 11 year old patient reported by Laforet $e t a l^{11}$ had "typical" DM at the age of 40 (age at onset not mentioned). All these congenitally affected patients were severely affected at birth or showed signs associated with DM in utero. Their affected fathers had mild or adult type DM, with age at onset beyond 30 years. In an earlier series of 132 congenitally affected children, reported by Harper, ${ }^{4}$ two certain cases and six probable instances of paternal transmission were found. However neither of these children had severe problems in the neonatal period or evidence of intrauterine abnormalities.

Imprinting, mutations of mitochondrial DNA, and transmission of a transplacental factor have been suggested to play a role in the maternal transmission of congenital DM. ${ }^{17-19}$ New insights have emerged with the recognition that an unstable CTG repeat is the mutational basis underlying DM and is the molecular explanation for anticipation in families. ${ }^{20}$ Patients with congenital DM have been shown, on average, to have longer CTG repeat sizes than those with adult and mild types of $\mathrm{DM} .{ }^{21}$ However, considerable variation exists, with the shortest repeat size found in congenital DM being about 500 CTG repeats, and the longest repeat size found in the adult type being about 2000 CTG repeats. ${ }^{2223}$

The sex and the repeat length of the transmitting parent are the main influences on the length of the CTG repeat in offspring. ${ }^{2024} 25$ Fathers with a small repeat expansion $(<100$ repeats) have a greater chance of significant expansion (up to $1000-1500$ repeats) in their offspring than mothers with a small repeat. ${ }^{20}{ }^{26}$ Fathers with longer repeats show a strong tendency to reduced amplification or even contraction of the repeat on transmission (repeat length in their offspring usually does not exceed 1000 repeats), presumably owing to negative selection of large DM alleles during spermatogenesis. ${ }^{1427} 28$ The fact that males with the adult type DM have, on average, fewer children than women with the same disease type also contributes to the lower frequency of paternal transmission of congenital DM. ${ }^{3}$

In mothers with a small DM mutation $(<100$ repeats), the repeat is often transmitted relatively stably to the next generation. ${ }^{20}$ However, a few asymptomatic women (with presumed CTG repeat sizes $<100$ ) have also been described who have given birth to children with congenital DM. ${ }^{25}{ }^{29}$ Cobo et $a l^{30}$ found that the risk of a congenitally affected child is considerably higher if the maternal allele is greater than 300 repeats. Only $10 \%$ of the affected children of mothers with a repeat length $<300$ showed the congenital form, while $60 \%$ of the affected offspring of mothers with a repeat length $>300$ were congenitally affected. ${ }^{30}$

Most of the published data are based upon measurements of repeat lengths in peripheral blood cells. Tissue heterogeneity for the DM mutation has been found, with larger expansions in muscle than in blood. ${ }^{14}{ }^{31}$ The impact of these observations on the inheritance pattern of congenital DM is not clear.

In conclusion the number of parental repeats, the sex of the transmitting parent, and the repeat size of the child are all important factors, but not the only features determining the congenital onset of the disease. Tissue heterogeneity is also hypothesised to play a role. The fact that sib 1 of the present family is congenitally affected, while sib 3 is not, despite having identically sized repeat expansions, cannot be fully explained on the basis of current knowledge about the characteristics of the unstable repeat in DM.

The reported observations of paternal transmission of congenital DM are of clinical importance, especially with regard to genetic counselling. Although paternal transmission of congenital DM is rare, a fertile man with DM has a small, but not negligible risk of producing a child with congenital DM. What is more, a man with age at onset $>30$ years, and hence the mild or late adult onset type, may have a greater chance of having a congenitally affected child than a father with earlier onset disease. The situation is complicated by the fact that the father himself may still be asymptomatic at the time of birth of the affected child. This is in contrast with the situation in affected women where the risk of a congenitally affected baby increases as the mother is more severely affected. Therefore myotonic dystrophy should be considered in either parent when a baby presents with severe muscular weakness and clinical and molecular studies of both parents should be carried out.

1 Koch MC, Grimm T, Harley HG, Harper PS. Genetic risks for children of women with myotonic dystrophy. Am $\mathcal{F} \mathrm{Hum}$ Genet 1991;48:1084-91.

2 Harley HG, Rundle SA, MacMillan JC, et al. Size of the unstable repeat sequence in relation to phenotype and parental transmission in myotonic dystrophy. Am $\mathcal{F}$ Hum Genet 1993;52:1164-74.

3 De Die-Smulders CEM, Höweler CJ, Mirandolle JF, et al. Anticipation resulting in elimination of the myotonic dystrophy gene: a follow up study of one extended family. $\mathcal{F}$ Med Genet 1994;31:595-601.

4 Harper PS. Myotonic dystrophy. 2nd ed. London: W B Saunders, 1989

5 O'Brien TA, Harper PS. Course, prognosis and complications of childhood-onset myotonic dystrophy. Dev Med Child Neurol 1984;26:62-7.

6 Fu YH, Pizzuti A, Fenwick RG Jr, et al. An unstable triplet repeat in a gene related to myotonic muscular dystrophy. Science 1992;255:1256-8.

7 Höweler CJ, Busch HFM, Geraedts JPM, et al. Anticipation in myotonic dystrophy: fact or fiction? Brain 1989;112:77997 .

8 Bergoffen J, Kant J, Sladky J, et al. Paternal transmission of congenital myotonic dystrophy. $\mathcal{F}$ Med Genet 1994;31:51820 .

9 Nakagawa M, Yamada H, Higuchi I, et al. A case of paternally inherited congenital myotonic dystrophy. $\mathcal{F}$ Med Genet 1994;31:397-400.

10 Ohya K, Tachi N, Chiba S, et al. Congenital myotonic dystrophy transmitted from an asymptomatic father with a DM-specific gene. Neurology 1994;44:1958-60.

11 Laforet P, Heron D, Gourdon G, et al. A new case of paternally inherited congenital myotonic dystrophy. Eur $\mathcal{F}$ Neurol 1995;2(suppl 1):29A.

12 Aslanidis C, Jansen G, Amemiya C, et al. Cloning of the essential myotonic dystrophy region and mapping of the putative defect. Nature 1992;355:548-51.

13 Mahadevan M, Tsilfidis C, Sabourin L, et al. Myotonic dystrophy mutation: an unstable CTG repeat in the 3

4 Jansen G, Willems P, Coerwinkel $M$, et al. Gonosomal mosaicism in myotonic dystrophy patients: involvement of mitotic events in (CTG) $)_{n}$ repeat variation and selection against extreme expansion in sperm. Am f Hum Genet against extreme

15 O'Hoy KL, Tsilfidis C, Mahadevan MS, et al. Reduction in size of the myotonic dystrophy repeat mutation during transmission. Science 1993;259:809-11. 
16 Jansen G, Mahadevan M, Amemiya C, et al. Characterization of the myotonic dystrophy region predicts multiple protein isoform-encoding mRNAs. Nat Genet 1992;1:261-6.

17 Harper PS, Dyken PR. Early onset dystrophia myotonica: evidence supporting a maternal environmental factor. Lancet 1972;ii:53-5.

18 Jansen G, Smeets $\mathrm{H}$, Kahisheuer V, et al. Myotonic dystrophy kinase (DM-kinase) gene expression in man and mouse. Am f Hum Genet Suppl 1993;53:233.

19 Poulton J, Harley HG, Dasmahapatra J, et al. Mitochondrial DNA does not appear to influence the congenital onset DNA does not appear to infuence the congenital onset

20 Wieringa B. Myotonic dystrophy reviewed: back to the future. Hum Mol Genet 1994;3:1-7.

21 Tsilfidis C, MacKenzie AE, Mettler G, et al. Correlation between CTG trinucleotide repeat length and frequency of severe congenital myotonic dystrophy. Nat Genet 1992;1 192-4.

22 Hunter A, Tsilfidis C, Mettler G, et al. The correlation of age of onset with CTG trinucleotide repeat amplification in myotonic dystrophy. 7 Med Genet 1992;29:774-9.

23 Barceló JM, Pluscauskas M, MacKenzie AE, et al. Additive influence of maternal and offspring DM-kinase CTG repeat lengths in the genesis of congenital myotonic dystrophy. Am f Hum Genet 1994;54:1124-5.
24 Brunner HG, Brüggenwirth HT, Nillesen W, et al. Influence of sex of the transmitting parent as well as of parental allele size on the CTG expansion in myotonic dystrophy. $\mathrm{Am} \mathrm{F}$ Hum Genet 1993;53:1016-23.

25 Redman JB, Fenwick RG Jr, Fu YH, et al. Relationship between parental trinucleotide GCT repeat length and severity of myotonic dystrophy in offspring. $\Im A M A$ 1993;269:1960-5.

26 Ashizawa T, Dunne PW, Ward PA, et al. Effects of the sex of myotonic dystrophy patients on the unstable triplet repeat in their affected offspring. Neurology 1994;44:120-2.

27 Ashizawa $T$, Anvret $M$, Baiget $M$, et al. Characteristics of intergenerational contractions of the CTG repeat in myotonic dystrophy. Am $\mathcal{f}$ Hum Genet 1994;54:414-23.

28 Brunner HG, Jansen G, Nillesen W, et al. Reverse mutation in myotonic dystrophy. N Engl F Med 1993;328:476-80.

29 Goodship J, Gibson DE, Burn J, et al. Genetic risk for children of women with myotonic dystrophy. Am f Hum Genet 1992;50:1341.

30 Cobo AM, Poza JJ, Martorell L, et al. Contribution of molecular analyses to the estimation of the risk of congenital myotonic dystrophy. $\mathcal{F}$ Med Genet 1995;32:105-8.

31 Zatz M, Passos-Buenos MR, Cerquira A, Vainzof M. CTG repeat length in muscle from patients with myotonic dystrophy (DM). F Med Genet 1996;33:173-6. 